\title{
Exigências nutricionais da grápia ao fósforo e enxofre em Argissolo Vermelho distrófico arênico: Efeito da adubação no crescimento
}

\author{
Nutritional demand of grápia to phophorus and sulfur in paleaudalf soil: fertilization \\ effects on growth
}

\author{
Evandro Luiz Missio $^{1}$ Fernando Teixeira Nicoloso $^{2}$ Gladis de Oliveira Jucoski ${ }^{3}$ \\ Lucas Sartori ${ }^{4}$
}

RESUMO

A grápia (Apuleia leiocarpa Vog. Macbride) é uma espécie de grande interesse madeireiro, encontrando-se, atualmente, bastante dizimada devido à exploração extrativista, sem haver reposição através de reflorestamento. O objetivo deste trabalho foi determinar os níveis ótimos de adubação de fósforo e enxofre no crescimento de plantas jovens de grápia. As plantas foram cultivadas em vasos contendo $3,5 \mathrm{~kg}$ de solo Argissolo Vermelho distrófico arênico, sob condições de casa de vegetação não climatizada. $O$ delineamento experimental foi o inteiramente casualizado com seis repetições. Foram avaliados 16 tratamentos em esquema bifatorial completo $(4 \times 4)$, representados pela combinação de quatro doses de P $\left(0,60,120\right.$ e $\left.180 \mathrm{mg} \mathrm{kg}^{-1}\right) e$ quatro de enxofre $\left(0,10,20\right.$ e $\left.30 \mathrm{mg} \mathrm{kg}^{-1}\right)$. A análise do crescimento das plantas foi realizada mensalmente através da altura da planta, diâmetro do caule e número de folhas remanescentes. Aos 130 dias após a emergência das plantas, avaliaram-se ainda o número de folhas caídas, matéria seca das folhas, caule, raízes e total da planta e a relação entre a matéria seca das raízes e da parte aérea. A produção de matéria seca total das plantas jovens de grápia respondeu positivamente à adubação conjunta de $P$ e $S$, com dose de máxima eficiência técnica estimada de, respectivamente, 204 e $16 \mathrm{mg} \mathrm{kg}^{-1}$ de solo. A adubação fosfatada na dose igual ou acima de $120 \mathrm{mg}^{\mathrm{kg}^{-1}}$ de solo induziu o aparecimento de clorose foliar típica da deficiência de Fe. A alta disponibilidade de $P$ no solo favoreceu o crescimento da parte aérea em detrimento das raízes.

Palavras-chave: espécie florestal, Apuleia leiocarpa, produção de mudas, nutrição mineral.

\section{ABSTRACT}

Grápia (Apuleia leiocarpa Vog. Macbride) is an important native forest species that has been in extinction process. The aim of this study was to determine the optimum levels of phosphorus and sulfur fertilization on the initial growth of grápia.
Grápia plants were cultivated in pots containing $3.5 \mathrm{~kg}$ of a Paleudalf soil, under unclimatized glasshouse conditions. Sixteen fertilization treatments were used in a complete bifactorial scheme (4x4), represented by the combination of four levels of $P\left(0,60,120\right.$, and $\left.180 \mathrm{mg} \mathrm{kg}^{-1}\right)$ and four levels of $S(0$, 10, 20, and $\left.30 \mathrm{mg} \mathrm{kg}^{-1}\right)$. The plant growth in height, stem diameter, and number of leaves was analyzed monthly. After 130 days of cultivation other growth parameters were analyzed, as follow: number of fallen leaves, dry weight of roots, stem, leaves, and of the whole plant, and root/shoot dry weight ratio. The dry weight of the whole plant positively responded to the combination of phosphorus and sulfur fertilization, with the maximum technical efficiency level of 204 and $16 \mathrm{mg} \mathrm{kg}^{-1}$ of soil, respectively. The phosphorus fertilization above $120 \mathrm{mg} \mathrm{kg}^{-1}$ of soil gave rise a chlorosis in leaves similar to that of $\mathrm{Fe}$ deficiency. High availability of $P$ in the soil was accounted for best growth of shoots in detriment of roots.

Key words: forest species, Apuleia leiocarpa, seedling production, mineral nutrition.

\section{INTRODUÇÃO}

A grápia (Apuleia leiocarpa Vog. Macbride) é uma espécie florestal que apresenta ampla distribuição geográfica no território brasileiro, porém atualmente se acha bastante descontínua, devido à devastação intensa das matas e à falta de reposição através do reflorestamento (MATTOS \& GUARANHA, 1983). Segundo REITZ et al. (1988), face às suas múltiplas aplicações, a grápia deve ser considerada como uma das mais valiosas madeiras do Rio Grande do Sul e, conseqüentemente, merece

\footnotetext{
${ }^{1}$ Engenheiro Agrônomo, MSc., em Agronomia, Pesquisador da Fundação Estadual de Pesquisa Agropecuária (FEPAGRO), Uruguaiana, RS. E-mail: evandrolmbr@yahoo.com.br

${ }^{2}$ Engenheiro Agrônomo, PhD., Professor Adjunto, Departamento de Biologia, Universidade Federal de Santa Maria (UFSM), 97105-900, Santa Maria, RS. Autor para correspondência. E-mail: nicoloso@base.ufsm.br .

${ }^{3}$ Engenheiro Florestal, Mestranda em Agronomia, UFSM.

${ }^{4}$ Engenheiro Agrônomo, UFSM.
} 
uma atenção especial nos estudos sobre a viabilidade de seu reflorestamento em larga escala.

A necessidade da determinação de níveis críticos dos nutrientes para cada espécie vegetal ou grupos de espécies afins, fundamenta-se não apenas em suas exigências nutricionais variáveis, mas também nas suas diferentes eficiências de absorção e/ou utilização dos nutrientes (BARROS \& NOVAIS, 1990; ABICHEQUER \& BOHNER, 1998).

A baixa disponibilidade de P no solo é uma das limitações mais comuns à produção agropecuária na América Latina Tropical, onde aproximadamente, $82 \%$ das solos são deficientes neste elemento (SANCHEZ \& SALINAS, 1981). Quanto aos níveis críticos de $\mathrm{P}$ no solo, observa-se a existência de distintos valores para diferentes espécies cultivadas num mesmo solo (FÖHSE et al., 1988; BARROS \& NOVAIS, 1990). Não obstante, é importante considerar que, pelo menos para plantas perenes, o nível crítico desse nutriente no solo provavelmente diminua com a idade da planta, conforme verificado para Eucalyptus por NOVAIS et al. (1990).

Estudando a relação entre o tempo de contato do adubo fosfatado no solo com a disponibilidade de $\mathrm{P}$ para as mudas de eucalipto, MOREIRA et al. (1991) observaram que a disponibilidade de P para o crescimento das mudas diminuiu com o aumento do tempo de contato do fertilizante fosfatado com o solo, particularmente naqueles cujas características indicam maior capacidade tampão.

Trabalhando com sete espécies vegetais anuais, FÖHSE et al. (1988) verificaram que a eficiência das plantas em relação ao P estava relacionada com a eficiência de absorção deste nutriente, a qual foi determinada pela razão entre o comprimento do sistema radicular e biomassa da parte aérea, bem como pela taxa de absorção por unidade de comprimento de raiz (influxo).

Para a grápia, submetida a três níveis $(0$, 40 e $80 \mathrm{mgkg}^{-1}$ ) de $\mathrm{N}$, de $\mathrm{P}$ e de $\mathrm{K}$ na adubação, NICOLOSO et al. (2001) constataram que: (i) a adubação fosfatada aumentou o crescimento das plantas em todos parâmetros avaliados, sendo que as maiores respostas, exceto para o comprimento do sistema radicular, ocorreram acima de $80 \mathrm{mgkg}^{-1}$; (ii) a aplicação de $\mathrm{K}$ em doses superiores a $60 \mathrm{mgkg}^{-1}$ influenciou positivamente o comprimento do sistema radicular, número de folhas, altura da planta e matéria seca da folha, caule e total da planta. Por outro lado, não alterou o diâmetro do caule, matéria seca da raiz e a relação entre a matéria seca das raízes e da parte aérea; e (iii) o efeito benéfico da adubação nitrogenada, quanto ao comprimento do sistema radicular, número de folhas, altura de planta, matéria seca de folhas e total da planta, foi condicionado à aplicação conjunta de K. Portanto, ficou demonstrado que a grápia é uma espécie muito exigente em $\mathrm{P}$ e medianamente exigente em $\mathrm{K}$ e $\mathrm{N}$ na fase inicial de crescimento, quando cultivada no solo Argissolo Vermelho distrófico arênico.

Quanto ao S, FRIEDRICH \& SCHRADER (1978) observaram que a deficiência de enxofre levou à redução da atividade da enzima nitrato redutase, ao acúmulo de nitrato e à redução nas concentrações de proteína solúvel e clorofila. Em experimentos de adubação com enxofre em mudas de cinco espécies de eucalipto, cultivadas em um Latossolo Vermelhoamarelo distrófico, FURTINI NETO et al. (1988) observaram que níveis de $\mathrm{S}-\mathrm{SO}_{4}{ }^{-2}$ no solo, variando entre 12 e $16 \mathrm{mg} \mathrm{kg}^{-1}$, ocasionaram a máxima produção de matéria seca, enquanto acima destes níveis, houve decréscimo de produção de biomassa em todas as espécies estudadas.

No geral, existem escassez de estudos sobre a disponibilidade do $\mathrm{S}$ no solo, sobre o efeito da adubação de $\mathrm{S}$ em espécies florestais, bem como informações das interações desse macronutriente em relação aos outros nutrientes, sobretudo com o N e P (BARROS \& NOVAIS, 1990).

O presente trabalho teve como objetivo avaliar os níveis ótimos de adubação de fósforo e enxofre no crescimento de plantas jovens de grápia (Apuleia leiocarpa Vog. Macbride).

\section{MATERIAL E MÉTODOS}

$\mathrm{O}$ experimento foi instalado em junho de 2000, na casa de vegetação não climatizada do Departamento de Fitotecnia do Centro de Ciências Rurais, na Universidade Federal de Santa Maria (UFSM), RS. Foram avaliados dezesseis tratamentos em esquema bifatorial completo $(4 \times 4)$, representados por quatro doses de $\mathrm{P}\left(0,60,120,180 \mathrm{mg} \mathrm{kg}^{-1}\right)$ e quatro doses de $\mathrm{S}\left(0,10,20\right.$ e $\left.30 \mathrm{mgkg}^{-1}\right)$. O delineamento experimental usado foi de tratamentos inteiramente casualizados, com seis repetições. A parcela experimental foi constituída de um vaso com $3,5 \mathrm{~kg}$ de terra fina seca ao ar e duas plantas, as quais foram submetidas a rodízio periódico para evitar algum efeito de localização na casa de vegetação. O solo utilizado no experimento foi coletado de 0 a $65 \mathrm{~cm}$ de profundidade do horizonte A de um Argissolo Vermelho distrófico arênico no município de Santa Maria, RS. Antes da instalação e no término do experimento realizaram-se as análises físicas e químicas do solo (Tabela 1). 
Tabela 1- Características físicas e químicas do horizonte A do solo ARGISSOLO VERMELHO Distrófico arênico antes e ao término do período experimental.

\begin{tabular}{|c|c|c|c|c|c|c|c|c|c|c|c|c|c|}
\hline \multirow{3}{*}{$\begin{array}{l}\text { Doses de } \\
\mathrm{S}-\mathrm{P} \\
\left(\mathrm{mg} \mathrm{kg}^{-1}\right)\end{array}$} & \multirow{3}{*}{$\begin{array}{l}\% \\
\text { argila } \\
\mathrm{m} / \mathrm{V}\end{array}$} & \multirow[t]{3}{*}{$\mathrm{pHH}_{2} \mathrm{O}$} & $\mathrm{P} *$ & $\mathrm{~K} *$ & $\mathrm{Ca}$ & $\mathrm{Mg}$ & \multirow{3}{*}{$\begin{array}{l}\% \text { M.O. } \\
\text { m/V }\end{array}$} & \multirow{3}{*}{$\begin{array}{l}\text { Sat. } \\
\text { Bases } \\
\%\end{array}$} & \multirow{3}{*}{$\begin{array}{l}\text { Sat. } \\
\mathrm{Al} \%\end{array}$} & $\mathrm{Cu}$ & $\mathrm{Zn}$ & \multirow[t]{3}{*}{$\mathrm{Fe}$} & \multirow[t]{3}{*}{ Mn } \\
\hline & & & & & & & & & & & & & \\
\hline & & & \multicolumn{2}{|c|}{$\mathrm{mg} \mathrm{L}^{-1}$} & \multicolumn{2}{|c|}{$\mathrm{cmol}_{\mathrm{c}} \mathrm{L}^{-1}$} & & & & \multicolumn{2}{|l|}{$\mathrm{mg} \mathrm{L}^{-1}$} & & \\
\hline$* *$ & 17 & 4,6 & 4,8 & 22 & 0,9 & 0,3 & 1,0 & 21 & 46 & 0,9 & 1,9 & 33 & 33 \\
\hline $0-0$ & 18 & 4,0 & 6,3 & 138 & 1,3 & 0,4 & 1,1 & 25 & 35 & 0,7 & 1,4 & 37 & 42 \\
\hline $0-60$ & 17 & 4,2 & 30 & 132 & 1,1 & 0,4 & 0,9 & 32 & 33 & 0,8 & 1,7 & 52 & 45 \\
\hline $0-120$ & 17 & 4,3 & 57 & 116 & 1,2 & 0,5 & 0,9 & 40 & 29 & 0,7 & 1,4 & 53 & 40 \\
\hline $0-180$ & 17 & 4,2 & 69 & 116 & 1,5 & 0,7 & 0,9 & 41 & 19 & 0,8 & 1,5 & 61 & 44 \\
\hline $10-0$ & 16 & 4,2 & 7,2 & 130 & 1,0 & 0,3 & 0,9 & 28 & 38 & 0,8 & 1,2 & 36 & 40 \\
\hline $10-60$ & 18 & 4,3 & 40 & 134 & 1,1 & 0,4 & 0,9 & 36 & 28 & 0,7 & 1,4 & 53 & 43 \\
\hline $10-120$ & 18 & 4,1 & 69 & 118 & 1,2 & 0,5 & 0,9 & 40 & 26 & 0,7 & 1,4 & 64 & 38 \\
\hline $10-180$ & 17 & 4,2 & 69 & 122 & 1,4 & 0,7 & 0,9 & 43 & 22 & 0,7 & 1,3 & 67 & 42 \\
\hline $20-0$ & 19 & 4,0 & 5,5 & 138 & 1,1 & 0,4 & 0,9 & 34 & 37 & 0,7 & 1,4 & 40 & 48 \\
\hline $20-60$ & 18 & 4,2 & 31 & 126 & 1,1 & 0,4 & 0,9 & 30 & 28 & 0,7 & 1,2 & 55 & 43 \\
\hline $20-120$ & 17 & 4,4 & 57 & 112 & 1,3 & 0,5 & 0,9 & 35 & 30 & 0,8 & 1,3 & 64 & 41 \\
\hline $20-180$ & 17 & 4,3 & 69 & 122 & 1,3 & 0,7 & 0,9 & 35 & 21 & 0,9 & 2,1 & 63 & 45 \\
\hline $30-0$ & 18 & 4,1 & 12 & 146 & 1,1 & 0,4 & 0,9 & 34 & 39 & 0,8 & 1,5 & 38 & 47 \\
\hline $30-60$ & 18 & 4,1 & 36 & 120 & 0,9 & 0,3 & 0,9 & 32 & 40 & 0,8 & 1,5 & 50 & 41 \\
\hline $30-120$ & 17 & 4,3 & 69 & 134 & 1,3 & 0,6 & 0,9 & 37 & 24 & 0,8 & 2,0 & 59 & 47 \\
\hline $30-180$ & 17 & 4,4 & 69 & 124 & 1,6 & 0,7 & 1,0 & 47 & 21 & 0,9 & 1,8 & 63 & 48 \\
\hline
\end{tabular}

* Extrator Mehlich-I; ** valores obtidos antes da instalação do experimento

Realizou-se uma adubação suplementar de $\mathrm{N}\left(100 \mathrm{mg} \mathrm{kg}^{-1}\right)$, de K $\left(100 \mathrm{mg} \mathrm{kg}^{-1}\right)$, de Ca (0 a 85,7mg $\left.\mathrm{kg}^{-1}\right)$ e de $\mathrm{Mg}\left(0 \mathrm{a} 42,9 \mathrm{mg} \mathrm{kg}^{-1}\right)$. As fontes de nutrientes foram o $\mathrm{Ca}\left(\mathrm{H}_{2} \mathrm{PO}_{4}\right)_{2}, \mathrm{KH}_{2} \mathrm{PO}_{4}, \mathrm{Na}_{2} \mathrm{SO}_{4}, \mathrm{KNO}_{3}$, $\mathrm{NH}_{4} \mathrm{NO}_{3}, \mathrm{NaNO}_{3}$ e $\mathrm{MgCl}_{2}$, todos sais PA. Manteve-se a relação $\mathrm{N}-\mathrm{NO}_{3}{ }^{-}$e N-NH${ }_{4}{ }^{+}$em 2:1, bem como a de $\mathrm{Ca}$ e $\mathrm{Mg}$ em 2:1. Todos os nutrientes foram aplicados na forma de solução nutritiva em dose única no momento da semeadura.

Os vasos foram pintados externamente com tinta branca para evitar o aquecimento excessivo devido à incidência de luz solar e, internamente, foram forrados com sacos plásticos contendo o solo, evitando a perda de água e nutrientes pela drenagem. Para reposição da água evapotranspirada, foi realizada irrigação, com água deionizada, sobre a superfície ou através de canos PVC perfurados e introduzidos no solo, mantendo-se a umidade do solo entre 40 e $60 \%$ da capacidade de campo, segundo método descrito por EMBRAPA (1979), por meio de aferições diárias por pesagem.

As sementes receberam escarificação química com $\mathrm{H}_{2} \mathrm{SO}_{4}$ concentrado, segundo método descrito por NICOLOSO et al. (1997), seguido de tratamento com solução fungicida a base de Benlate (Benomyl) a 0,2\%. Após procedeu-se a semeadura (21/ 06/2000) de quatro sementes diretamente nos vasos.
Após a emergência das plântulas (04/07/2000), realizou-se (15/07/2000) a seleção das mesmas deixandose duas por vaso.

A análise do crescimento foi feita mensalmente após a emergência das plantas, avaliando-se o diâmetro do caule, a altura da planta e o número de folhas remanescentes. No término do experimento, aos 130 dias, foram avaliados o número de folhas caídas e a produção da matéria seca das folhas, do caule, das raízes e total da planta, bem como a relação entre a matéria seca das raízes e da parte aérea.

A análise estatística dos resultados observados baseou-se na análise de regressão, em nível de probabilidade de erro de $5 \%$.

\section{RESULTADOS E DISCUSSÃO}

Os diferentes parâmetros de crescimento avaliados apresentaram respostas isoladas à adubação de $\mathrm{P}$, bem como interação entre $\mathrm{P}$ e S. O diâmetro do caule (Figura 1a) e o número de folhas por planta (Figura 1b) aumentaram com a adubação fosfatada. Todavia, o número de folhas respondeu mais rápido à adubação de $\mathrm{P}$, demonstrando que o crescimento $\mathrm{e}$ o desenvolvimento das folhas é drasticamente dependente da disponibilidade desse macronutriente (LYNCH et al., 1991). Mesmo que o diâmetro do 
caule, aos 120 dias após a emergência (DAE), e o número de folhas por planta, aos 120 e 130 DAE, tenham apresentado resposta cúbica à adubação de $\mathrm{P}$, as doses de máxima eficiência técnica estimada (DMET) à adubação foram sempre acima da maior dose (180 $\left.\mathrm{mg} \mathrm{kg}^{-1}\right)$ utilizada em todas épocas avaliadas.

Quanto ao número de folhas caídas aos 130

DAE, o incremento da disponibilidade de $\mathrm{P}$ provocou redução na queda de folhas (Figura 1c). Também trabalhando com mudas de grápia, NICOLOSO et al. (1999) constataram que a omissão de P da adubação, em Argissolo Vermelho distrófico arênico, foi a que mais limitou o crescimento das plantas quanto ao número de folhas remanescentes, a partir dos $48 \mathrm{DAE}$ das plantas.

Apesar da adubação fosfatada diminuir a abscisão foliar, verificou-se, a partir da dose de $120 \mathrm{mg}$ $\mathrm{kg}^{-1}$ de solo, o aparecimento visual de clorose foliar típica da deficiência de Fe. Este fenômeno tem sido observado para outras espécies vegetais quando submetidos à alta disponibilidade de P (OLSEN, 1972). A presença da adubação fosfatada aumentou $o$ teor de $\mathrm{P}$ no solo, sendo na ordem de 10 vezes na dose de $180 \mathrm{mgkg}^{-1}$ (Tabela 1). Interessantemente, o teor de Fe no solo também aumentou em função do incremento da disponibilidade de $\mathrm{P}$, porém numa proporção de apenas duas vezes (Tabela 1). Vários fatores podem provocar deficiência de $\mathrm{Fe}$ nas plantas, tais como: baixo nível de $\mathrm{Fe}$ no solo, alto nível de $\mathrm{P}$ no solo, temperaturas extremas, diferenças genéticas, baixo conteúdo de matéria orgânica em solos ácidos e $\mathrm{CaCO}_{3}$ livre (LUCAS \& KNEZEK, 1972). Destes fatores, pode-se inferir como tendo influenciado no estabelecimento da deficiência de Fe na grápia, o alto nível de $\mathrm{P}$ no solo (Tabela 1) devido a adubação realizada, o baixo conteúdo de matéria orgânica (Tabela 1) e a alta temperatura do ambiente (temperatura máxima acima de $30^{\circ} \mathrm{C}$ nos últimos 45 do período experimental).

Para a altura da planta, também se verificou que as DMET à adubação fosfatada foram acima da maior dose utilizada, a partir dos 90 DAE (Figura 1d). Também para a grápia cultivada em Argissolo Vermelho distrófico arênico, NICOLOSO et al. (2001) constataram que a DMET à adubação de $\mathrm{P}$ para a altura da planta foi acima da maior dose utilizada $\left(80 \mathrm{mg} \mathrm{kg}^{-1}\right)$. Respostas diferenciadas à adubação fosfatada têm sido relatadas para várias espécies florestais. DANIEL et al. (1997) observaram resposta quadrática à adubação de $\mathrm{P}$ no diâmetro do caule e altura de Acacia mangium. FERNANDES et al. (2000) verificaram respostas diferenciadas entre aroeirinha (Schinus terenbinthifolius), paineira (Chorisia speciosa) e jambolão (Syzygium jambolanum) à adição de $\mathrm{P}$, sendo que a paineira apresentou as melhores respostas em diâmetro de caule e número de folhas com adubação entre 300 e $600 \mathrm{mgkg}^{-1}$.

Quanto à produção de biomassa, observouse resposta isolada à adubação de $\mathrm{P}$ para a matéria seca do caule, folha e parte aérea (Figura 2a), com DMET acima da maior valor utilizado. A biomassa das raízes (Figura 2b) e total da planta (Figura 2c) apresentaram resposta de interação à adubação de $\mathrm{P} e$ $\mathrm{S}$, sendo que a DMET média foi de, respectivamente,

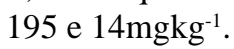

Níveis semelhantes de resposta ao $\mathrm{S}$ foram observados por FURTINI NETO et al. (1988) em eucalipto cultivado em Latossolo Vermelho-amarelo distrófico. Além disso, estes autores verificaram que das cinco espécies de eucalipto estudadas, a $\boldsymbol{E}$. pilularis, $\boldsymbol{E}$. pellita e $\boldsymbol{E}$ citriodora foram as mais responsivas à adubação, enquanto $\boldsymbol{E}$. grandis e $\boldsymbol{E}$. camaldulensis foram consideradas menos responsivas. Portanto, os dados da literatura evidenciam a importância de se considerar a interação solo versus espécie vegetal.

Trabalhando com a técnica do nutriente faltante na adubação de um Argissolo Vermelho distrófico arênico, NICOLOSO et al. (1999) verificaram que a omissão isolada de $\mathrm{P}, \mathrm{S}, \mathrm{N}$ e K da adubação induziram os piores resultados no crescimento da grápia, demonstrando, portanto, que estes nutrientes foram os mais limitantes nesse solo para o crescimento inicial dessa espécie florestal.

Comportamento semelhante em relação à adubação fosfatada na produção de biomassa da grápia foram obtidos por RESENDE et al. (1999), estudando diferentes grupos de espécies florestais em Latossolo Vermelho-Escuro, e também por OLIVEIRA et al. (1998), avaliando a resposta de angelim-pedra (Dinizia excelsa Ducke) em Argissolo Vermelho distrófico arênico. Já BARBOSA et al. (1997) obtiveram respostas lineares crescentes para a matéria seca de raízes, do caule, de folhas e total da planta de aroeira-do-sertão (Myracrodruon urunduva Fr. All.) pelo aumento da adubação de $\mathrm{P}$ até $450 \mathrm{mg} \mathrm{kg}^{-1}$. Estes mesmos autores também constataram decréscimo na relação da matéria seca das raízes e da parte aérea com o aumento das doses de P. Fato também registrado em Picea sitchensis por PROE \& MILLARD (1995).

A razão entre a matéria seca de raízes e da parte aérea diminuiu em função do incremento da adubação de P (Figura 2d). Estes resultados corroboram aqueles anteriormente observados para a grápia (NICOLOSO et al., 2001), aroeira-do-sertão 


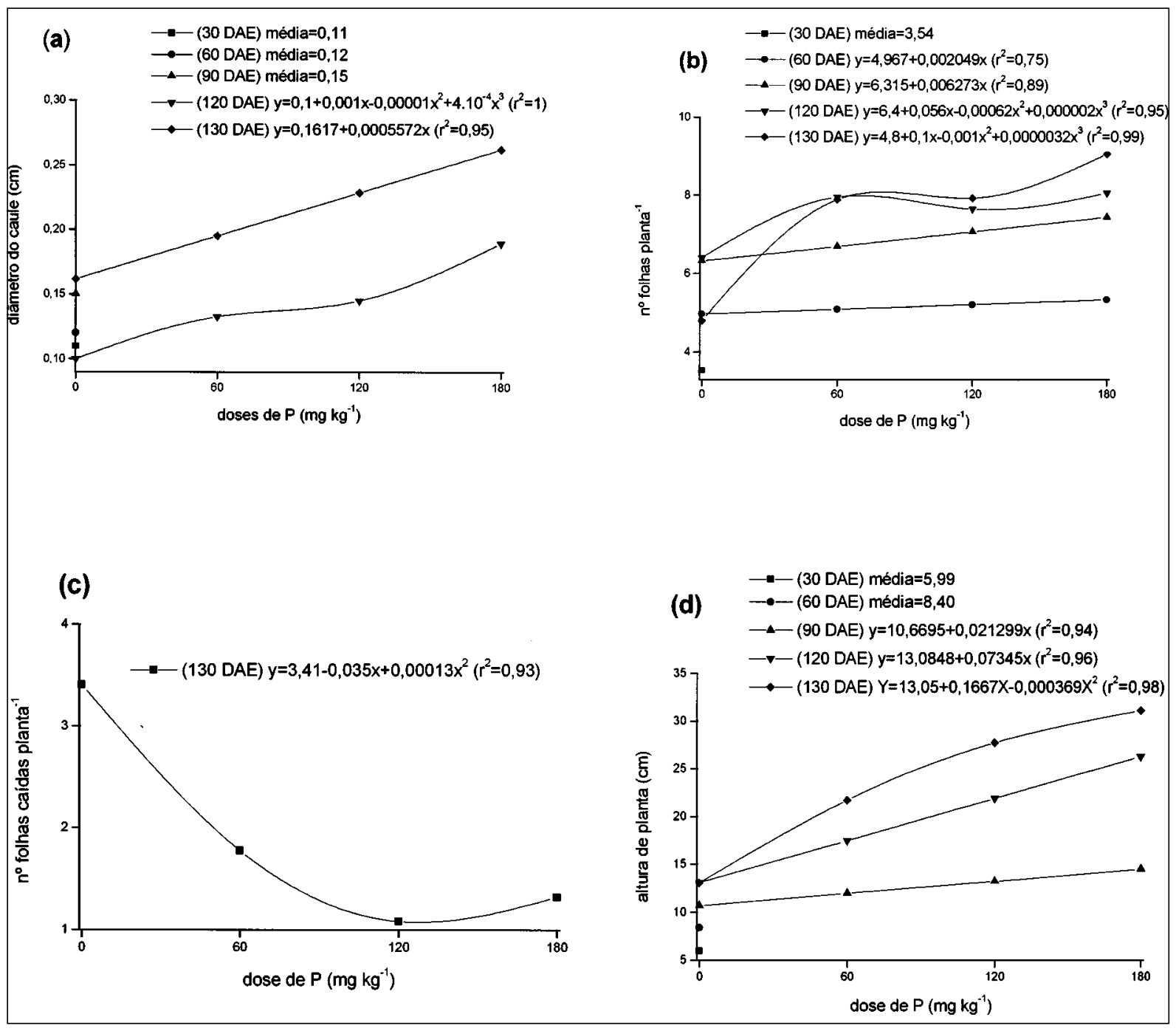

Figura 1 - Efeito da adubação isolada de fósforo no diâmetro do caule (a), número de folhas remanescentes (b), número de folhas caídas (c) e altura de plantas (d) jovens de grápia, cultivadas em Argissolo Vermelho distrófico arênico.

(Myracrodruon urunduva Fr. All.) (BARBOSA et al., 1997) e Acacia magium (DANIEL et al., 1997). Como o P é praticamente imóvel no solo e apresenta-se com frequiência em baixas concentrações na maioria dos solos brasileiros, entre 1 a 10 $\mathrm{mg} \mathrm{kg}^{-1}$ (MALAVOLTA, 1980), as plantas são submetidas a um estresse nutricional que pode desencadear mecanismos adaptativos, visando ao aumento da disponibilidade e absorção de P (FÖHSE et al., 1988; ERICSSON, 1995; RAGHOTHAMA, 1999). Apesar do P movimentar-se principalmente no solo via processo de difusão (MARSCHNER, 1995), a interceptação radicular, através de um maior crescimento do sistema radicular em relação à parte aérea, também permite melhorar a exploração do solo e absorção de $\mathrm{P}$ (FÖHSE et al., 1988; RAGHOTHAMA, 1999). Por outro lado, quanto maior for a disponibilidade de $\mathrm{P}$, menor é a relação entre a matéria seca de raízes e da parte aérea (BARROS \& NOVAIS, 1990; ERICSSON, 1995; MARSCHNER, 1995).

Os resultados apresentados para a grápia, no presente trabalho, corroboram aqueles relatados por NICOLOSO et al. (1999, 2001), ou seja fica demonstrada a limitação potencial do Argissolo Vermelho distrófico arênico para sustentar o cultivo da grápia sem a correção da sua fertilidade natural.

\section{CONCLUSÕES}

A dose de máxima eficiência técnica estimada à adubação de $\mathrm{P}$ e $\mathrm{S}$ na produção de matéria seca da planta foi de 204 e $16 \mathrm{mg} \mathrm{kg}^{-1}$ de solo, respectivamente. A alta disponibilidade de $\mathrm{P}$ no solo favo- 


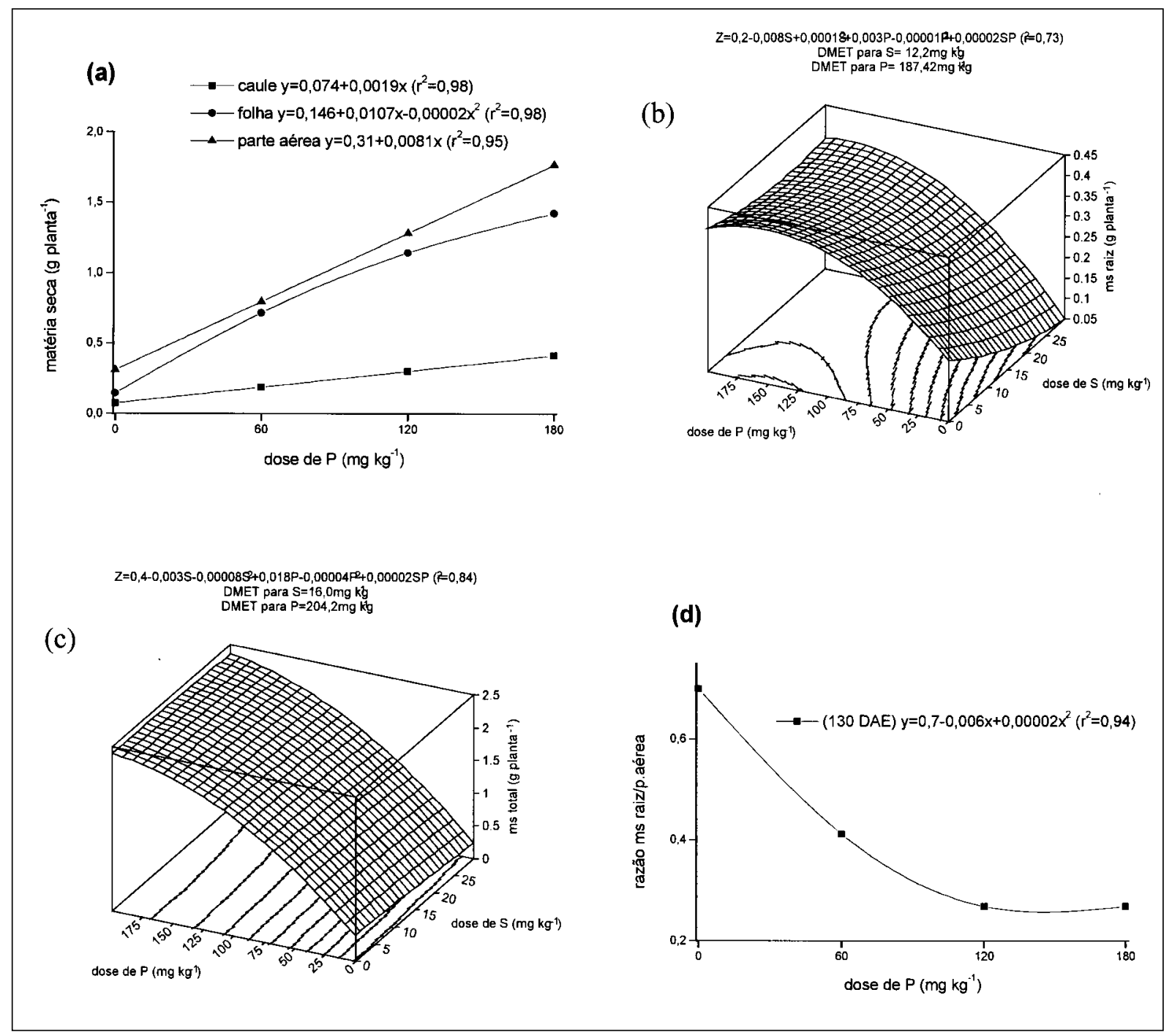

Figura 2 - Efeito da adubação isolada de P ou em conjunto com S na matéria seca do caule, folha e parte aérea (a), matéria seca de raízes (b), matéria seca total da planta (c), e razão da matéria seca das raízes e da parte aérea (d) de plantas jovens de grápia, cultivadas em Argissolo Vermelho distrófico arênico.

receu o crescimento da parte aérea em detrimento das raízes, bem como induziu o aparecimento de clorose foliar típica da deficiência de Fe.

\section{REFERÊNCIAS BIBLIOGRÁFICAS}

ABICHEQUER, A.D.; BOHNER, H. Eficiência de absorção, translocação e utilização de fósforo por variedades de trigo. Revista Brasileira de Ciência do Solo, Campinas, v.22, n.1, p. 21-26, 1998.

BARBOSA, Z.; CARVALHO, J.G.; MORAIS, A.R. Fósforo e zinco na nutrição e crescimento da aroeira-do-sertão. I. Características de crescimento das plantas. Ciência e Agrotecnologia, Lavras, v.21, n.2, p. 196-204, 1997.

BARROS, N.F.; NOVAIS, R.F. de. Relação solo-eucalipto. Viçosa: Folha de Viçosa, 1990. 330p.
DANIEL, O. et al. Aplicação de fósforo em mudas de Acácia mangium Wild. Revista Árvore, Viçosa, v.21, n.2, p.163-168, 1997.

EMBRAPA. Serviço nacional de levantamento e conservação do solo: manual de métodos e análise de solos. Rio de Janeiro: EMBRAPA, 1979. 650p.

ERICSSON, T. Growth and shoot: root ratio of seedlings in relation to nutrient availability. Plant and Soil, Netherlands, v.168-169, p.205-214, 1995.

FERNANDES, L.A. et al. Crescimento inicial, níveis críticos de fósforo e frações fosfatadas em espécies florestais. Pesquisa Agropecuária Brasileira, Brasília, v.35, n.6, p.1191-1198, 2000.

FÖHSE, D.; CLAASSEN, N.; JUNGK, A. Phosphorus efficiency of plants. I - External and internal P requirement and P uptake

Ciência Rural, v. 34, n. 4, jul-ago 2004. 
efficiency of different plant species. Plant and Soil, Netherlands, v.110, p.101-109, 1988 .

FRIEDRICH, J.W.; SCHRADER, L.E. Sulfur deprivation and nitrogen metabolism in maize seedlings. Plant Physiology, Baltimore, v.61, n.6, p.900-903, 1978.

FURNTINI NETO, A.E. et al. Efeito do enxofre no crescimento de cinco espécies de eucalipto. Revista Árvore, Viçosa, v.12, n.1, p.1-11, 1988.

LUCAS, R.E.; KNEZEK, B.D. Climatic and soil conditions promoting micronutrient deficiencies in plants. In: MORTVEDT, J.J.; GIORDANO, P.M.; LINDSAY, W.L. (Ed.). Micronutrients in agriculture. Madison : Soil Science Society of America, 1972. Cap.12, p.265-288.

LYNCH, J., LÄUCHLI, A, EPSTEIN, E. Vegetative growth of the common bean in response to phosphorus nutrition. Crop Science, Madison, v.31, p.380-387, 1991

MALAVOLTA, E. Elementos de nutrição mineral de plantas. São Paulo : Agronômica Ceres, 1980. 251p.

MARSCHNER, H. Mineral nutrition of higher plants. London Academic, 1995. 890p.

MATTOS, N.F.; GUARANHA, J. Contribuição ao estudo da grápia (Apuleia leiocarpa). Porto Alegre : Instituto de Pesquisas de Recursos Naturais Renováveis “AP”, 1983. 25p. (Boletim Técnico 12).

MOREIRA, J.F. et al. Efeito do tempo de contato do fósforo com o solo sobre sua disponibilidade para mudas de eucalipto. Revista Brasileira de Ciência do Solo, Campinas, v.15, n.3, p.303-308, 1991.

NOVAIS, R.F.; BARROS, N.F.; NEVES, J.C.L. Nutrição mineral do eucalipto. In: BARROS, N.F.; NOVAIS, R.F. de. Relação solo-eucalipto. Viçosa : Folha de Viçosa, 1990. Cap.2, p.25-98.

NICOLOSO, F.T. et al. Efeito de métodos de escarificação na superação da dormência de sementes e dois substratos na germinação e no desenvolvimento da grápia (Apuleia leiocarpa). Ciência Rural, Santa Maria, v.27, n.3, p.419-424, 1997.

NICOLOSO, F.T. et al. Exigências nutricionais da grápia (Apuleia leiocarpa Vog. Macbride) em solo Podzólico vermelho amarelo. Ciência Rural, Santa Maria, v.29, n.2, p.225231, 1999.

NICOLOSO, F.T. et al. Nutrição mineral de mudas de grápia em argissolo vermelho distrófico arênico: (I) Efeito da adubação NPK no crescimento. Ciência Rural, Santa Maria, v.31, n.6, p.991998, 2001.

OLIVEIRA, J.M.F.; SILVA, A.J.; SCHWENGBER, D.R. Resposta de mudas de angelim-pedra a nitrogênio e fósforo. Pesquisa Agropecuária Brasileira, Brasília, v.33, n.9, p.1503-1507, 1998.

OLSEN, S.R. Micronutrient interations. In: MORTVEDT, J.J.; GIORDANO, P.M.; LINDSAY, W.L. (Ed.). Micronutrients in agriculture. Madison: Soil Science Society of America, 1972. Cap.11, p.243-264.

PROE, M.F.; MILLARD, P. Effect of P supply upon seasonal growth and internal cycling of $\mathrm{P}$ in sitka spruce (Picea sitchensis (Bong.) Carr.) seedlings. Plant and Soil, Dordrecht, v.168, p.313317, 1995.

RAGHOTHAMA, K.G. Phosphate acquisition. Annual Review of Plant Physiology and Plant Molecular Biology, Palo Alto, v.50, p.665-693, 1999 .

REITZ, R., KLEIN, R.M.; REIS, A. Projeto madeira do Rio Grande do Sul. Porto Alegre : Corag, 1988. 525p.

RESENDE, A.V.; FURTINI NETO, A.E.; MUNIZ, J.A. Crescimento inicial de espécies florestais de diferentes grupos sucessionais em resposta a doses de fósforo. Pesquisa Agropecuária Brasileira, Brasília, v.34, n.11, p.2071-2081, 1999.

SÁNCHEZ P.A.; SALINAS, J.G.. Low-input technology for managing oxisols and ultisols in tropical América. Advances in Agronomy, New York, v.34, p.279-406, 1981. 